\title{
Possibility of Forming Periodic Pulse Jets Using Cavitation Self-Oscillations Modes
}

\author{
I.I. Kozlov, S.A. Ocheretyany, V.V. Prokofiev \\ Institute of Mechanics, Lomonosov Moscow State University, Moscow, 119192, Russia \\ vlad.prokof@yandex.ru
}

\begin{abstract}
Cavitation self-oscillations are studied, which occurs during liquid flow in a line with two resistances: the first cavitator, which followed by artificial ventilated cavity is formed with an average pressure greater than atmospheric pressure, through the second resistance (nozzle) liquid and gas flow into the atmosphere. Experiments were carried out on a flat jet plant. Through the transparent side walls of the current was videotaped. The possibility of using self-oscillations mode to create periodic pulse jets at the output is being studied. The studies have shown that different frequency modes of self-cycling can be implemented, with the mode of the first or second frequency modes being the most suitable for generating pulse jets. It is shown that at sufficiently high average pressure in the cavity the mode of intermittent liquid outflow from the nozzle is realized. The maximum pressure in the area of collision with the obstacle significantly exceeds both the average pressure of the head and the maximum pressure in the cavity.
\end{abstract}

Keywords: jet flow, cavity, negative cavitation number, cavitation self- oscillations, pulsation technologies
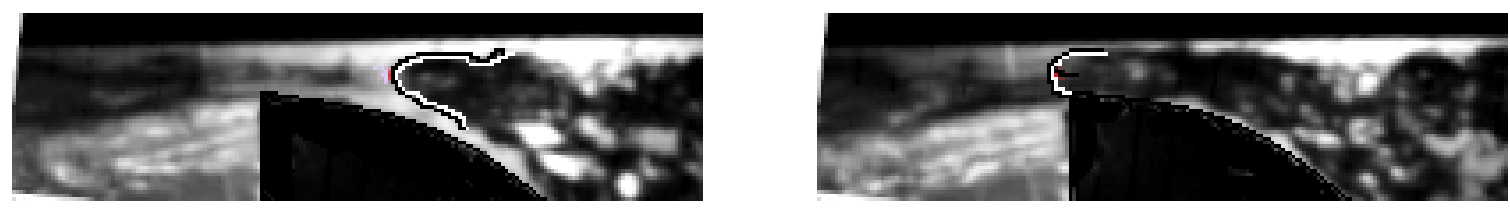

Shape of the leading edge at the expiration of the next portion of liquid from the Voytsekhovsky nozzle

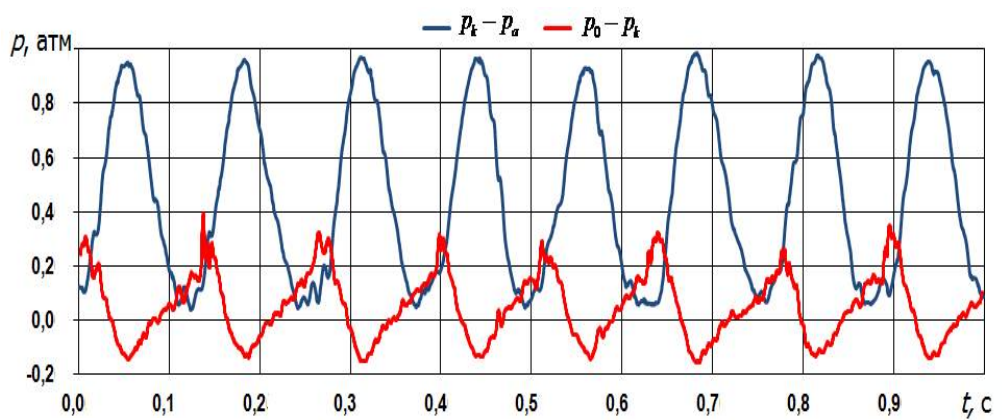

Liquid portion formation: blue curve - pulsation of excess pressure in the cavity, red curve - pressure difference in the head camera and cavity. When $p_{0}-p_{k}>0$ the portion is generated, when $p_{0}-p_{k}<0$ the leakage from the head camera locked

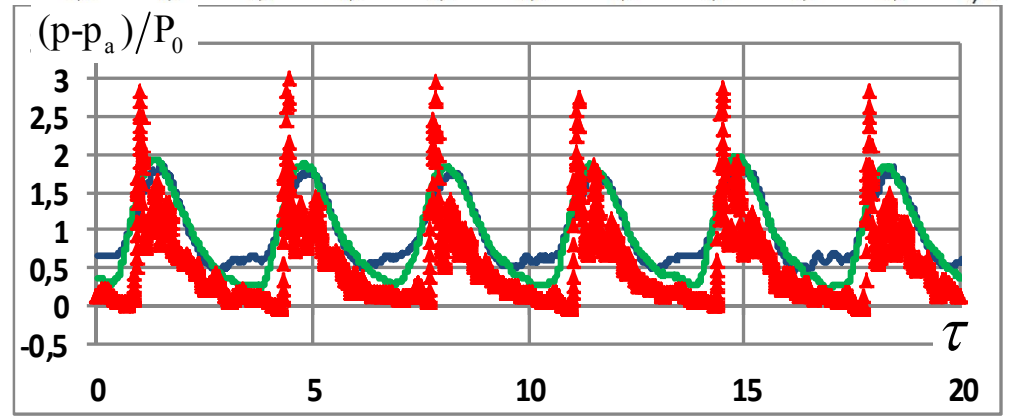

Dimensionless pressure oscillograms in the head camera (blue curve) and in the cavity (green) are shown, red points are pressure pulses in the area of impact into the screen. You can see that the pressure pulse on the screen is significantly higher than the maximum pressure in the cavity and in the head camera 


\title{
О возможности формирования периодических импульсных струй с использованием кавитационных автоколебательных режимов
}

\author{
И.И. Козлов, С.А. Очеретяный, В.В. Прокофьев \\ Научно-исследовательский институт механики МГУ им. М.В. Ломоносова, \\ Россия, Москва, 119192, Мичуринский проспект, 1 \\ vlad.prokof@yandex.ru
}

\begin{abstract}
Аннотация
Изучаются кавитационные автоколебания, возникающие при течении жидкости в магистрали с двумя сопротивлениями: первое кавитатор, за которым образована искусственная вентилируемая каверна со средним давлением большим атмосферного, через второе сопротивление (сопло) происходит истечение жидкости и газа в атмосферу. Эксперименты проводились на плоской струйной установке, через прозрачные боковые стенки которой проводилась видеосъемка течения. Изучается вопрос о возможности использования режима автоколебаний для создания на выходе периодических импульсных струй. Исследования показали, что могут реализовываться различные частотные моды автоколебаний, причем наиболее подходящим для создания импульсных струй представляется режим первой или второй частотных мод. Показано, что при достаточно высоком среднем давлении в каверне реализуется режим прерывистого истечения жидкости из сопла. Максимальное давление в области соударения с препятствием значительно превосходит как среднее давление напора, так и максимальное давление в каверне.
\end{abstract}

Ключевые слова: струйное течение, каверна, отрицательное число кавитации, кавитационные автоколебания, пульсационные технологии.

\section{1. Введение}

Исследования способов разрушения материалов высоконапорными струями, проводимые различными научными коллективами, показали, что их эффективность сильно зависит от характера прилагаемых нагрузок: статические (непрерывные) или динамические (пульсирующие), которые создаются струей жидкости, воздействующей на разрушаемый объект. Как показывают исследования [1], действие статических нагрузок (непрерывной струи) сопровождается образованием демпферной подушки, которая препятствует разрушению обрабатываемого материала. При прерывисто - переменных динамических нагрузках (пульсирующие струи) демпферная подушка не образуется и происходит интенсификация процессов щелеобразования и раскалывания материала, следствием которых является рост производительности. Кроме того, взаимодействие прерывистой струи с препятствием сопровождается явлением гидроудара, давление в котором значительно превосходит давление при стационарном взаимодействии.

Для успешного применения гидродинамических способов создания пульсирующих струй необходимы эффективные и удобные в эксплуатации устройства, формирующие импульсные струи требуемых параметров. Этой проблеме посвящено много работ [2-5]. Как правило, в таких установках используются механические устройства, обеспечивающие пульсирующую работу. Например, в воздушном пульсаторе [2] пульсации создаются за счет периодического введения порции воздуха в струю жидкости, в гидроимпульсаторе [3] исполь- 
зуется внешний генератора колебаний совместно с гидропневмоаккумулятором. В устройствах, использующих гидроударные импульсные насадки [3], колебания возникают за счет возвратно-поступательного движения клапана, в гидромониторах с подвижной насадкой [4] - путем быстрого надвигания насадки на струю. Преобразователь давления, описанный в работе [5] использует цапфовый распределитель, который на одной половине оборота соединяются с напорной, а на другой - со сливной магистралями приводной насосной станции источника воды высокого давления. Там же описан генератор импульсной струи (ГИС), который осуществляет преобразования высоконапорного потока малого расхода в импульсный поток повышенного расхода используя накопитель и гидропневмоаккумулятор. В устройстве используется система клапанов, поршней и т.п.

С другой стороны, известен пример струйного течения в гидравлической системе, где имеют место устойчивые интенсивные автоколебательные режимы при постоянных параметрах, подаваемых в систему воды и воздуха, без каких-либо механических систем, возбуждающих колебания. Это течения в трубе с образованием за препятствием (кавитатором) искусственной вентилируемой каверны, замыкание которой происходит перед вторым сопротивлением - диафрагмой, соплом и т. п. (см. работы авторов $[6,7,8]$ и группы сотрудников МГТУ [9]). При определенных условиях реализуется развитый автоколебательный режим близкий к прерывистому течению с весьма малым потреблением жидкости. Представленная работа является продолжением [8], в первой части для ясности изложения приведены некоторые основные экспериментальные факты, изложенные ранее в работе [8]. Дополнительно здесь представлены результаты экспериментов на новой рабочей части, где исследуется влияние на автоколебания положения и формы выходного сопла, влияние объема каверны на частоту и интенсивность пульсаций давления. Приведены экспериментальные данные об ударном воздействии периодических струй на преграду. В последнем разделе простейшая одномерная модель применена к оценке помпажного режима течения, когда жидкость в виде отдельных масс периодически истекают в атмосферу через сужающееся сопло. Параметры этого течения задаются на базе полученной ранее экспериментальной информации. Проведены оценки масштабного эффекта при увеличении давления напора, а также влияния объема каверны на процесс «выстрела».

\section{2. Кавитационные автоколебания в гидравлических системах}

\section{1. Плоская струйная экспериментальная установка}

На рис. 1 показана общая схема установки для изучения кавитационных течений. Вода в установку поступает из бака-демпфера 2, где пульсации давления выравниваются воздушной подушкой. Для исследования влияния свойств трубопровода между фланцами 3 и 4 подводящего к рабочей части трубопровода устанавливаются трубы различной длины и с различными свойствами, подача воздуха в каверну регулируется вентилем 8 , который работает в режиме аэродинамического запирания. Для этого на нем поддерживается большой перепад давления - давление в воздушной магистрали примерно $60 \mathrm{MПа,} \mathrm{давление} \mathrm{в} \mathrm{каверне} \mathrm{порядка}$ 10 МПа. Таким образом, пульсационное течение имеет место в подводящей воду магистрали, в форкамере рабочей части установки и в каверне. На рис. 2 показана схема плоской рабочей части - течение жидкости и газа происходит в зазоре шириной 9 мм между двумя прозрачными толстостенными пластинами из оргстекла. Подача воды и воздуха осуществляются по нормали к пластинам, вода из форкамеры 5 истекает через щель 2 шириной $D=25$ мм между вертикальной стенкой и горизонтальной вставкой 1 с острой кромкой, за которой образуется газовая каверна (препятствие с острыми кромками за которыми образуется газовая каверна в литературе часто называют кавитатором). Здесь показан вариант стационарного предельного (будем его называть критическим) струйного течения, когда истекающая в атмосферу через щель 4 шириной $H$ струя имеет точку касания с горизонтальным экраном 7. Если давление в каверне меньше этого критического - взаимодействие с экраном может быть смоделировано 
схемой с разделением струй, а при давлении большем критического - граница каверны не взаимодействует с экраном 7 - каверна становится разомкнутой. В конфигурации рис. 2 длина каверны $L$ есть сумма длины свеса щита 3 (50 мм) и ширины выходной щели 4.

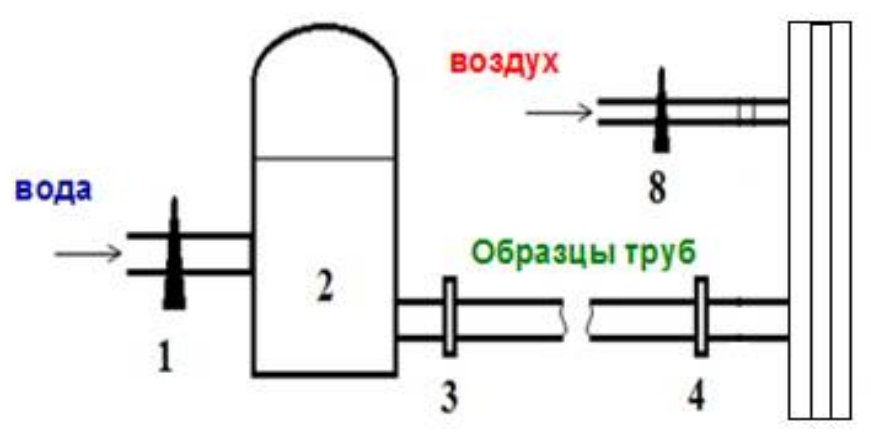

Рис. 1. Схема установки

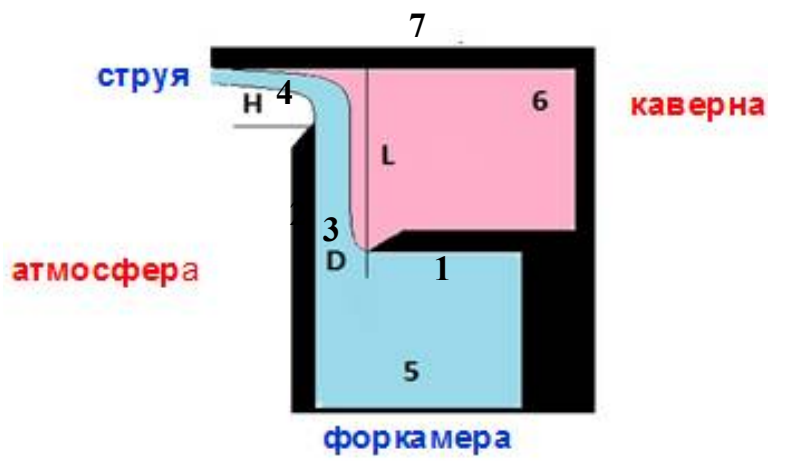

Рис. 2. Плоская рабочая часть

$$
C_{d}=\frac{\bar{p}_{k}-p_{a}}{\bar{p}_{0}-p_{a}}=\frac{P_{k}}{P_{0}}, \quad C_{q}=\frac{Q_{g}}{Q_{l}}, \quad S h=f \frac{D}{V_{\infty}}, \quad V_{\infty}=\sqrt{\frac{2 P_{0}}{\rho_{l}}}
$$

Введены безразмерные величины: коэффициент давления в каверне, коэффициент поддува газа и число Струхаля ( $C_{d}, C_{q}, S h$, соответственно). Здесь $\bar{p}_{0}, \bar{p}_{k}, p_{a}$ - осредненные по времени давления в форкамере, каверне и атмосферное давление; $Q_{l}, Q_{g}$ - объемные расходы жидкости и газа; $f$ - частота пульсаций.

\section{2. Пример развитых кавитационных автоколебаний}

Представленный здесь пример иллюстрирует динамику и кинематику развитых колебаний. На рисунке $3, a, \sigma, 6,2$ - результат обработки осциллограмм давления в каверне, совместно с синхронной видеозаписью для модели рис. 2 показан режим развитых автоколебаний при среднем для периода наблюдения избыточном давлении в форкамере $P_{0}=0.2$ атм.

На рис. 3, $a$ даны последовательные кадры одного периода течения. Рисунок 3, 6 - осциллограмма избыточного по сравнению с атмосферой давления в каверне; рис. 3, в - изменение во времени координаты гребня волн, распространяющихся от кромки кавитатора $(X=0)$ до экрана $(X=50$ мм); рис. 3, г - $Y$ координата границы раздела между газом и выбрасываемым вдоль экрана объемом жидкости.

$\mathbf{a}$
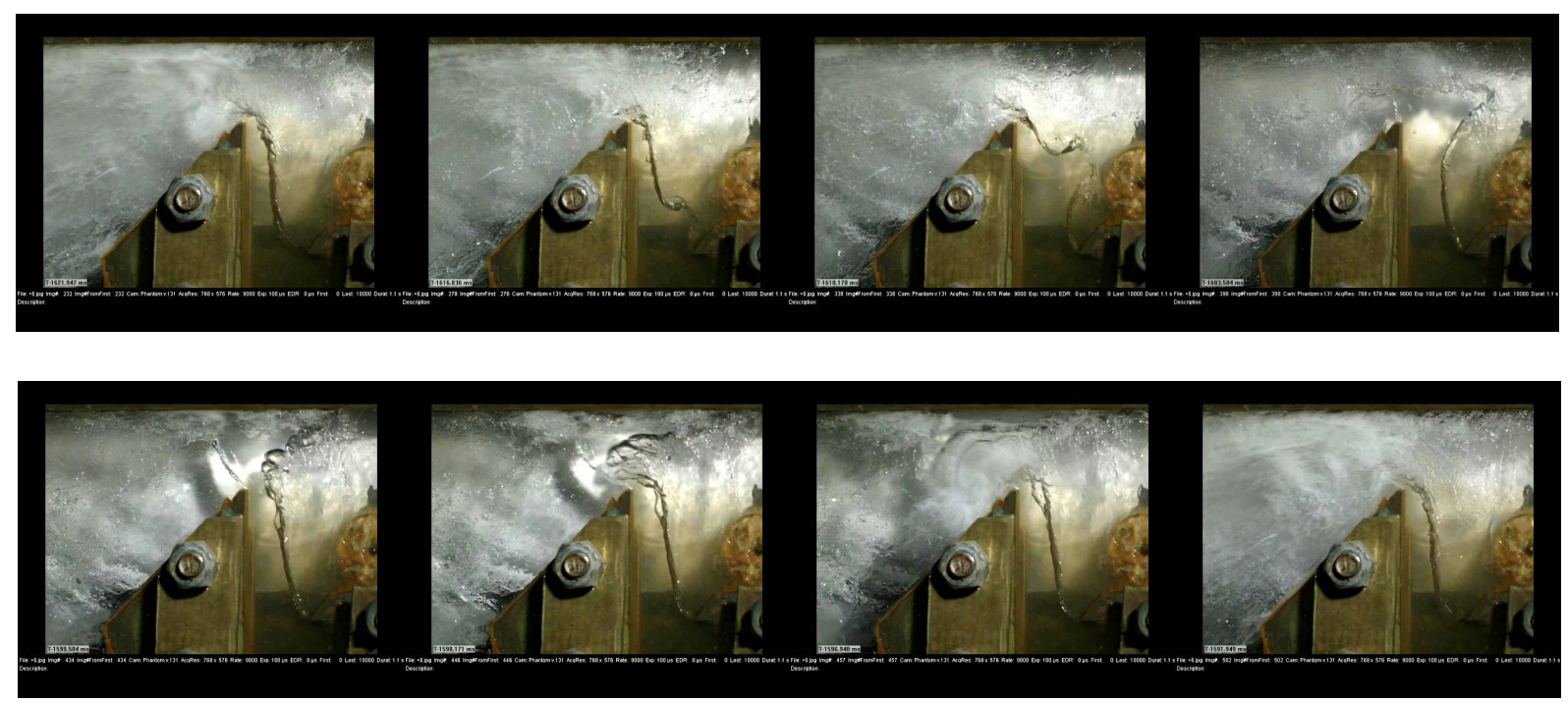
б
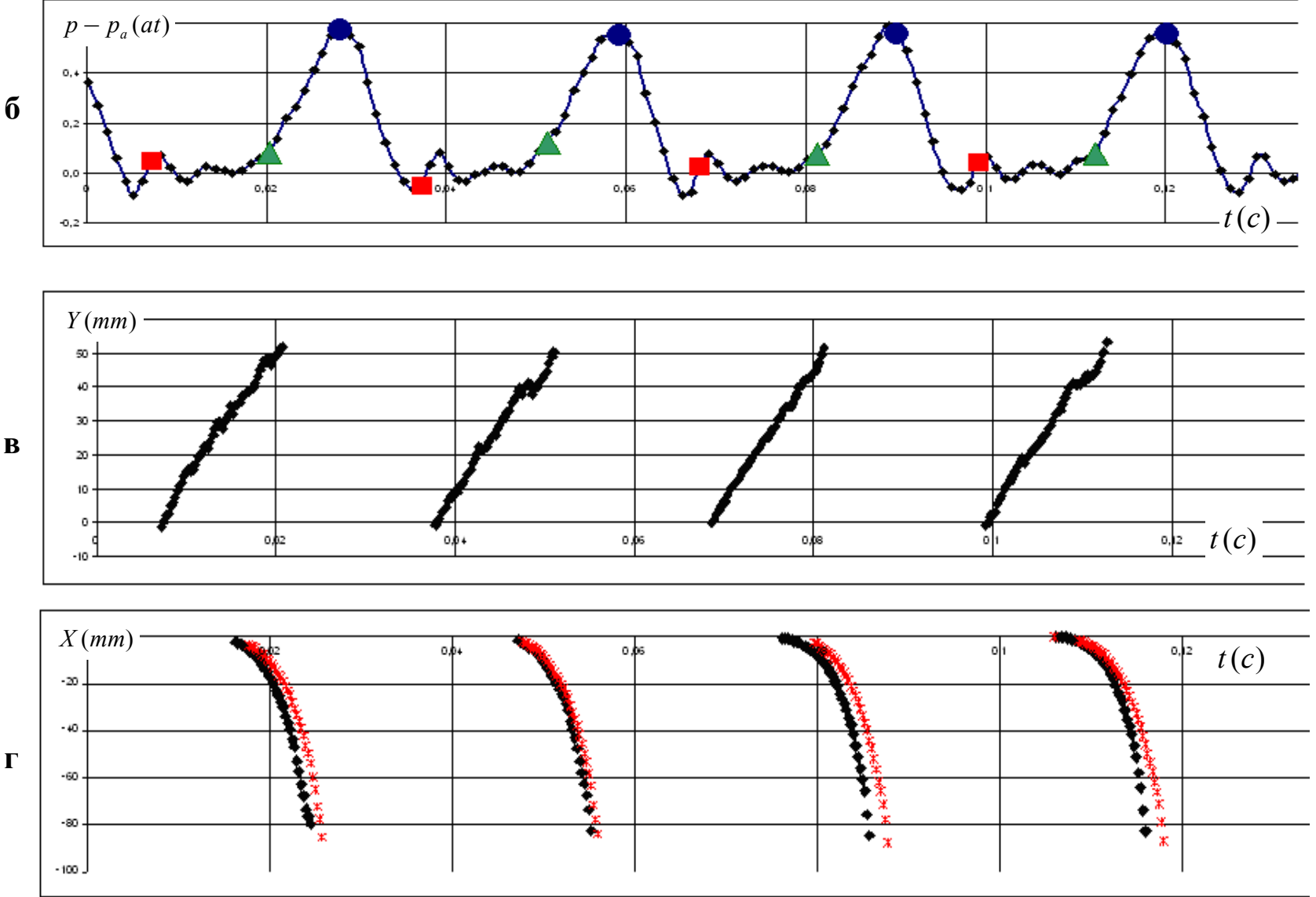

Рис. 3. Кадры одного периода автоколебательного течения (a), осциллограмма 4-х периодов (б) и расшифровка соответствующей видеограммы $(6,2)$

Видно (рис. 3, в), что волна вдоль границы каверны распространяется почти с постоянной скоростью (было показано, что эта скорость близка к скорости соответствующего стационарного течения). Красные квадраты на осциллограмме (рис. 3,6 ) соответствуют началу движения волны от кавитатора, зеленые треугольники моменту, когда волна достигает экрана. С этого момента начинается стадия выбрасывания порции жидкости через щель в атмосферу. Синие круги соответствуют моменту разрушения выбрасываемой водяной пробки (крайние справа точки на рис. 3, , при $Y \sim-80$ мм - черные и красные точки кривых показывают возможный разброс данных).

\section{3. Пример возникновения различных мод автоколебаний при одинаковой геометрии течения}

Если период колебаний связать со временем прохождения волны вдоль границы каверны длиной $L$ и предположить, что скорость волны равна $V_{k}-$ скорости жидкости на границе каверны при стационарном течении (в качестве давления напора и давления в каверне приняты средние по времени величины, измеренные в эксперименте), тогда $V_{k}=V_{\infty} \sqrt{1-C_{d}}$ и для числа Струхаля можно написать [8]

$$
S h=N \frac{V_{k} D}{V_{\infty} L}=N \frac{D}{L} \sqrt{1-C_{d}},
$$

где $N$ - число волн вдоль границы каверны (или номер моды). Следует иметь в виду, что этой формулой можно пользоваться для оценок частоты автоколебаний, если время перемещения волны вдоль каверны значительно больше времени истечения порции жидкости через щель 4 (или сопло) и, если граница каверны начинается на кромке кавитатора (т.е. в процессе коле- 
баний не происходит прорыва воздуха в область перед кавитатором). Вообще же говоря, числа Струхаля не должны превосходить величины, полученные по этой формуле, так как период процесса равен сумме времени распространения волны вдоль каверны и времени истечения жидкости в атмосферу через выходное сопло.

На рис. $4, a, \sigma, 6,2$ представлены примеры осциллограмм пульсаций давления в форкамере (сплошные линии) и в каверне (штрихи) для четырех частотных режимов автоколебаний при одинаковых геометрических параметрах (использовалась рабочая часть, показанная на рис. 2) и приметно одинаковых коэффициентах поддува $C_{q} \sim 20$. Различные режимы колебаний были получены при различных параметрах подводящей трубы и различных объемах каверны (см. [8]). Избыточное давление на рис. 4, $a, \sigma, 6$, , отнесено к $P_{0}$, время к $T_{w}=L_{k} / V_{k}$. Масштаб времени $T_{w}$ здесь соответствует времени прохождения волны от кавитатора 2 (рис. 2) до экрана 7. Видно, что на рис. 4, а (первая мода) эта величина соответствует периоду колебаний, на рис. 4,б двум периодам и т.д. до 4-й моды (рис.4, 2), т.е. в полном соответствии с формулой (1). Следует обратить внимание, что на высших модах наиболее интенсивные колебания возбуждаются в напорных трубах и форкамере - в режиме 4-й моды они даже выше чем в режиме 1-й. Интенсивность же осцилляций в каверне падает в 5-6 раз по сравнению с первой модой. Так как жидкость выбрасывается наружу под действием высокого давления в каверне, режимы высоких мод (здесь 3-я и 4-я моды) для создания импульсных струй непригодны, а вот 1-я и 2-я моды представляют интерес.

a. Первая мода

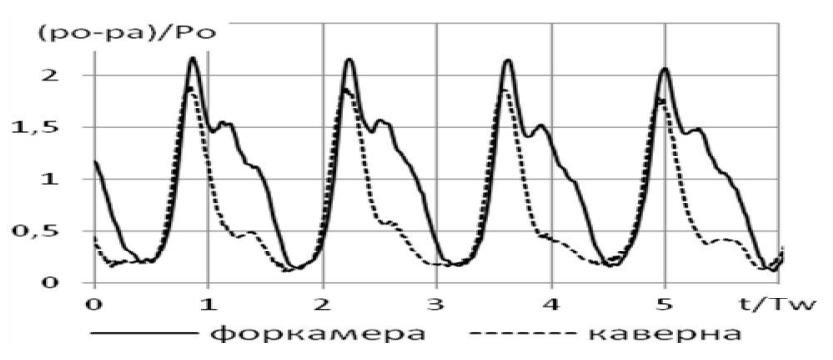

в. Третья мода

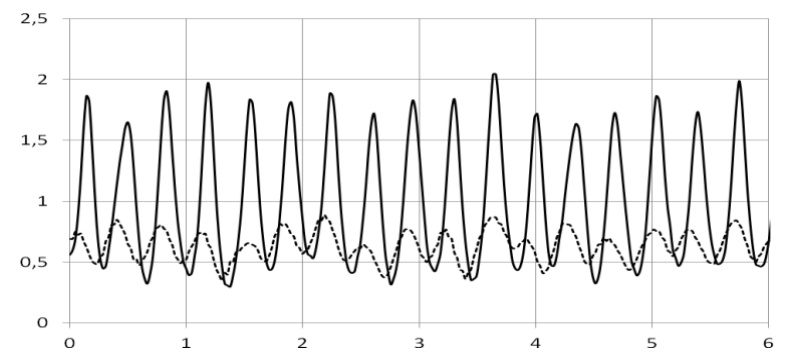

б. Вторая мода

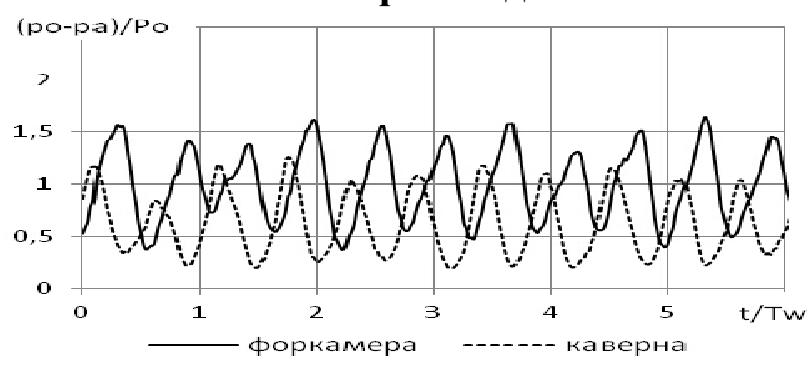

2. Четвертая мода

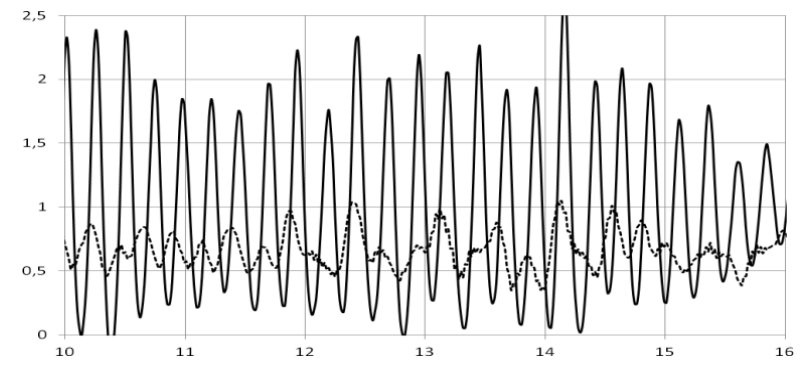

Рис. 4. Осциллограммы давления в форкамере (сплощная линия) и каверне (штрихи) для различных частотных мод ( $a, \sigma, 6,2$ соответствуют $1,2,3$ и 4-й модам колебаний)

\section{4. Автоколебания при истечении через сопло Войцеховского}

Видеограммы рис. 3, а показывают, что при выбрасывании жидкости из щели происходит ее разбрызгивание. На первом этапе исследований влияния формы выходного сопла на автоколебания [8] было использовано сходящееся экспоненциальное сопло Войцеховского, форма которого задавалась формулой (см. [10])

$$
S(x)=h H(x)=S_{1} e^{-b x}, \quad b=0.611 \frac{\left(L+H_{1}\right)}{D H_{1}}
$$

Одна стенка сопла являлась продолжением свеса (3, на рис. 2); плоский экран (7, на рис. 2) вторая стенка плоского сопла; $H(x)$ - ширина сопла; $S(x)=h H(x)$ - площадь сечения. Здесь 
обозначено: $h$ - величина зазора между боковыми параллельными пластинами плоской рабочей части; $x$ - координата вдоль экрана; $H_{1}=50$ мм ширина входного сечения сопла; параметр экспоненты $b$ выбирался согласно методике [10]. Выходное сечение варьировалось: $H=20,10,5,7$ мм (соответственно увеличивалось выходное сопротивление). С уменьшением выходного сечения сопла $H$ наблюдается увеличение $C_{d}$ (рис. 5,8 ), при $H=5$ мм среднее давление в каверне столь близко к среднему давлению в форкамере, что в процессе пульсаций происходит прорыв воздуха из каверны в форкамеру (и даже в напорный трубопровод), что резко снижает пульсации уже при умеренных величинах поддува воздуха.

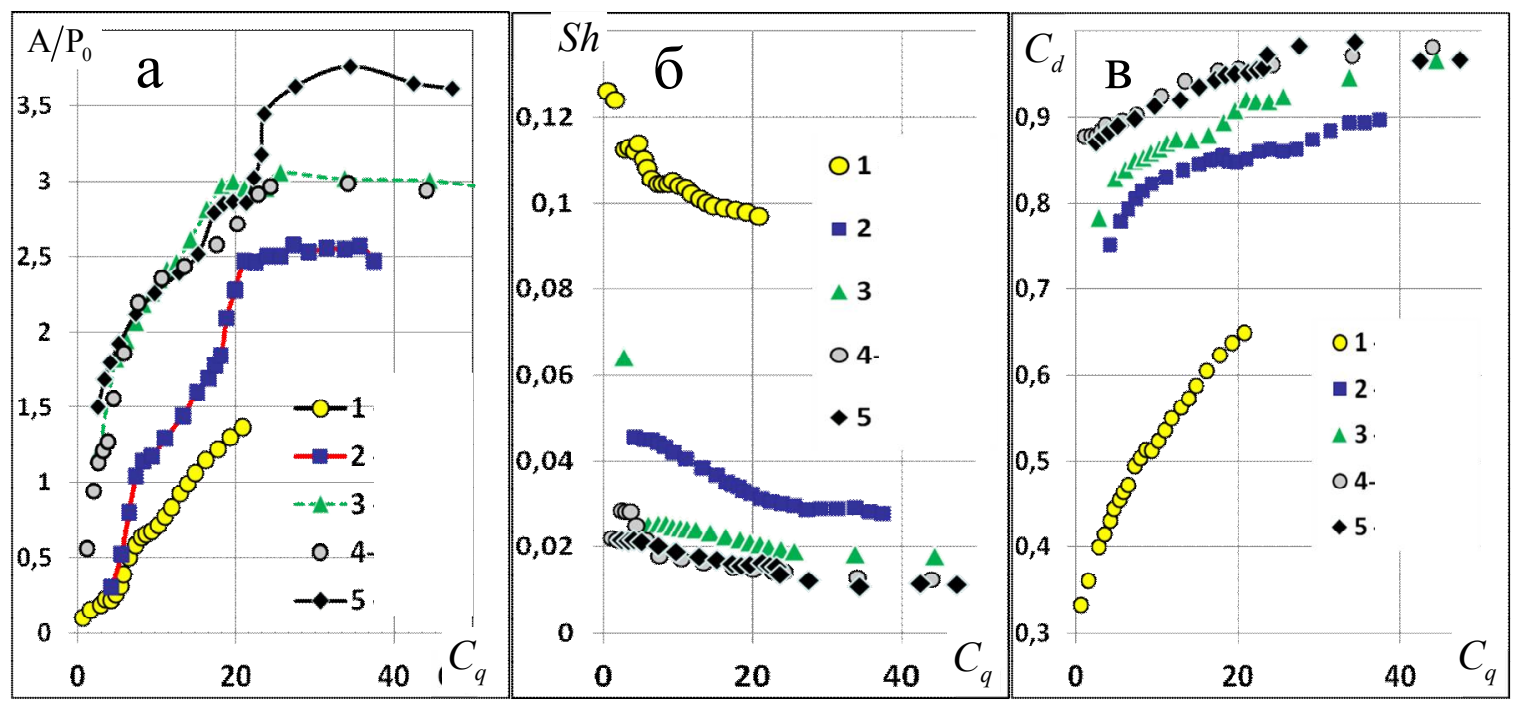

Рис. 5. Зависимости относительной интенсивности пульсаций давления в каверне $(a)$, числа Струхаля (б) и коэффициента давления в каверне (в) от поддува для различных $H$. Цифры 1,2 , 3, 4 на графиках соответствуют ширине выходного сечения сопла $H=54,20,10,5,7$ мм

Максимальная амплитуда наблюдалась при ширине выходного сечения сопла $H=7$ мм при коэффициентах поддува больших 20 (кривая 5 на рис. $5, a$ ). Для сравнения на рис. $5, a, \sigma, 6$ представлены данные для истечения в отсутствие сопла - через щель шириной 54 мм (кривые обозначены цифрой 1). Нужно отметить, что наибольшие пульсации давления в каверне наблюдаются при коэффициентах расхода больших 20, то есть в установке расход жидкости невелик по сравнению с расходом газа.

\section{5. Видеограмма истечения порции жидкости через плоское сопло Войцеховского}

На рис. 6, $а$ проиллюстрирован процесс истечения порции жидкости через сопло Войцеховского, которое использовалось М.А. Лаврентьевым и Б.В.Войцеховским для создания водяных импульсных струй [10]. Условия истечения: характерная скорость $V_{\infty}=10 \mathrm{~m} / \mathrm{c}$ $\left(P_{0}=0.5\right.$ атм), $C_{d}=0.93, C_{q}=8$, шаг кадров $2.7 \times 10^{-4}$ c. На кадрах черный цвет внизу - плоский профиль сопла Войцеховского (ширина выходного сечения $H=5$ мм), вверху плоский экран. Виден передний фронт истекающей из сопла жидкой массы. По видеограмме определено изменение $X$ координаты переднего фронта истекающей жидкости ( $X=0$ соответствует выходному сечению сопла), закон движения переднего фронта хорошо аппроксимируется кубическими полиномами (см. рис. $5, \sigma$ ). По этим аппроксимациям определен закон изменения скорости фронта (см. рис. 5, 6). Разные кривые построены для 3-х периодов колебаний одной видеограммы (1-й, 4-й и 7-й периоды колебаний, периоды отмечены на осциллограмме - рис. 7) - видна хорошая повторяемость процесса. На выходе из сопла скорость в 3.5 раза превосходит скорость стационарного истечения. Но главное здесь это прерывистый характер истечения, который предполагает ударное взаимодействие с объектом. На рис. 7 для этого случая представлена осциллограмма пульсаций давления в каверне и разности давлений в 
форкамере и каверне. Вблизи максимума давления в каверне величина $p_{0}-p_{k}$ отрицательна - истечение жидкости из форкамеры в каверну не происходит, в это же время происходит выброс жидкости через сопло наружу. В фазе пониженного давления в каверне, величина $p_{0}-p_{k}$ положительна - происходит интенсивное истечение из форкамеры в каверну - формируется порция жидкости.
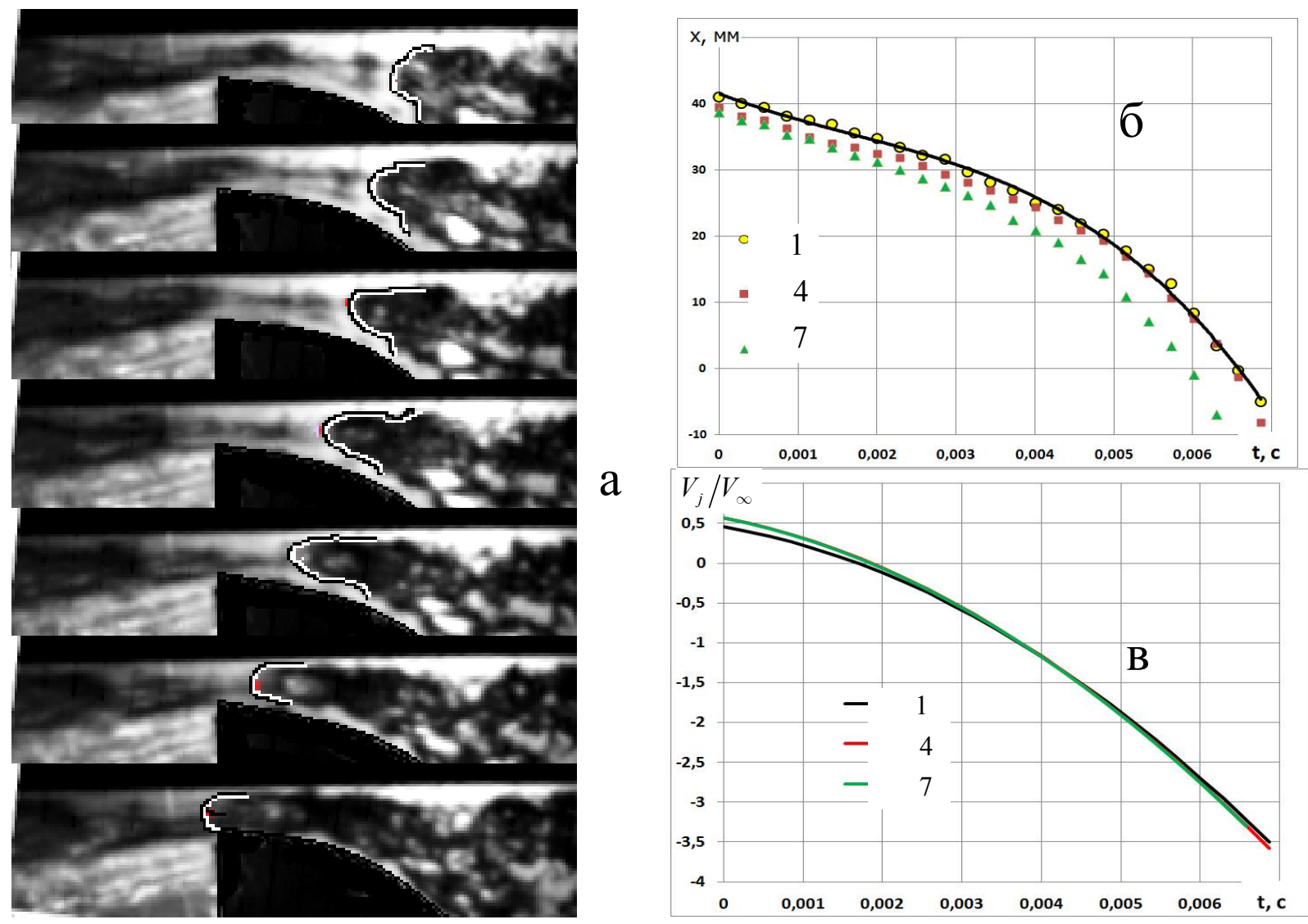

Рис. 6. Кинограмма истечения порции жидкости из сопла Войцеховского $(a)$; изменение $X$ координаты переднего фронта истекающей жидкости (б) (цифрами 1, 4, 7 обозначены выбранные для обработки периоды колебаний - см. рис. 7), сплошная кривая - аппроксимация кубическими полиномами данных для 1-го периода; в - построенные по аппроксимациям графики изменения скорости переднего фронта истекающей жидкости $V_{j}$

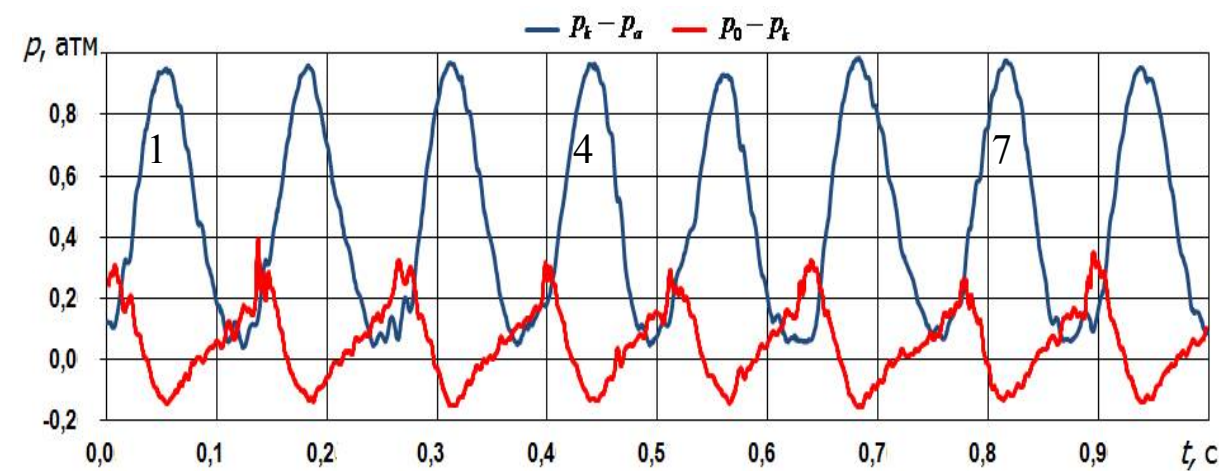

Рис. 7. График осцилляций избыточного давления в каверне и разности давлений в форкамере и каверне

\section{6. Влияние объема каверны на истечение периодических струй}

Для исследования удара прерывистой струи о препятствие используется измененная по сравнению с рис. 2 рабочая часть (рис. 8). Здесь струя не ударяется об перпендикулярный ей 
экран, а сначала попадает в сужающееся сопло (вход 25 мм, выходное сечение 10 мм, стенка имеет форму $18^{0}$ клина), истекает вдоль прямолинейной стенки и взаимодействует с перпендикулярным экраном на расстоянии 34 мм от среза сопла. В точке удара производилось измерение пульсаций давления $p_{m}$ (точки замера давления на рис. 8 обозначены соответствующими буквами).

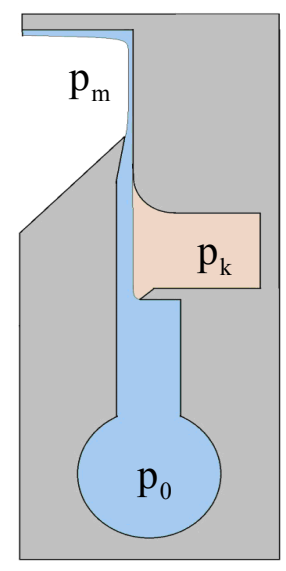

Рис. 8 Схема рабочей части

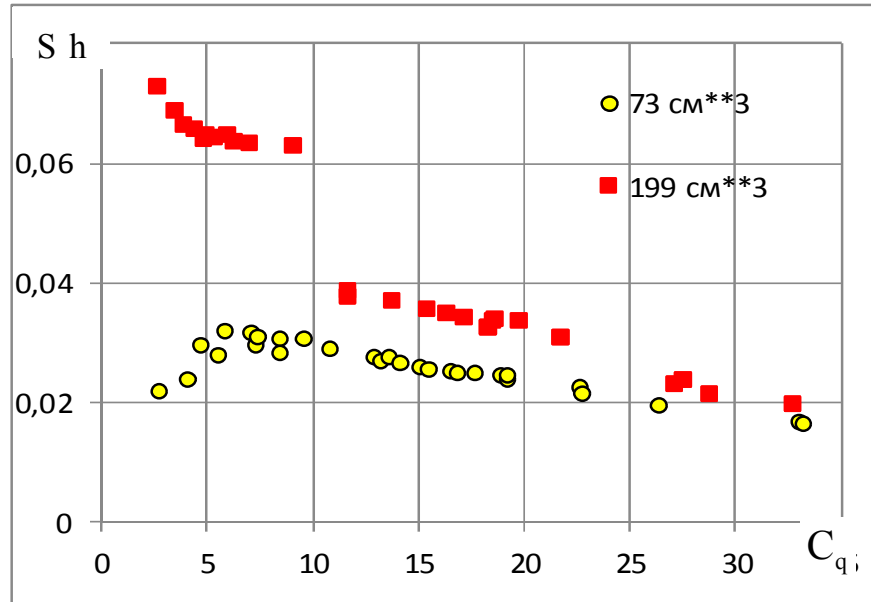

Рис. 9, $a$. Зависимость числа Струхаля для двух значений объема каверны

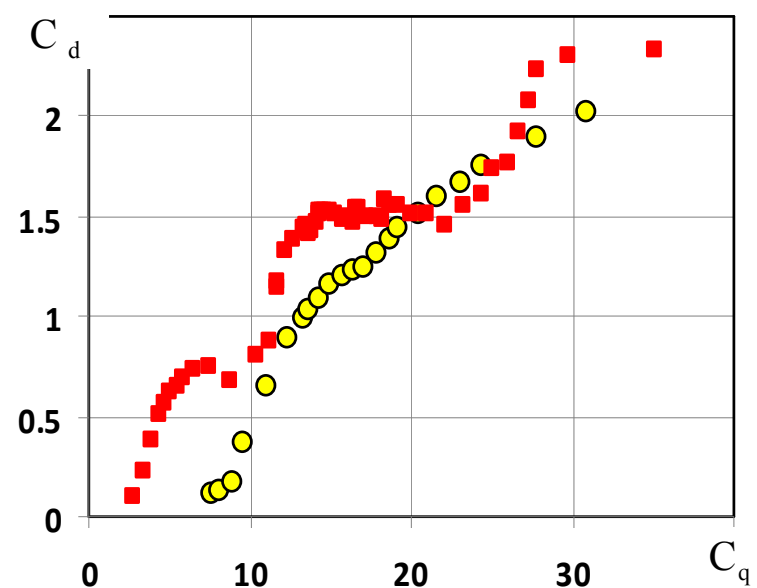

Рис. 9, б. то же для коэффициента давления в каверне

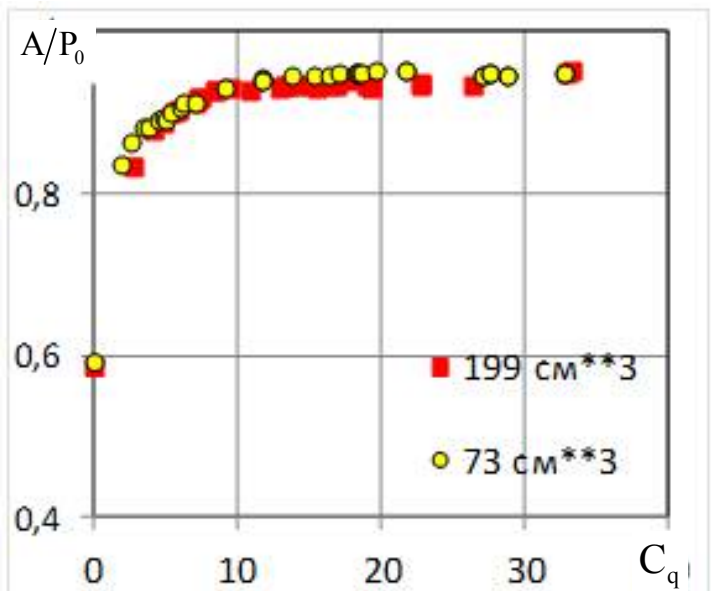

Рис. 9, в. то же для относительной интенсивности пульсаций давления в каверне

На рис. 9, $a, \sigma$, в показано изменение числа Струхаля, коэффициента среднего давления в каверне и обезразмеренного размаха колебаний давления в каверне в зависимости от коэф- 
фициента расхода. Среднее избыточное давление в форкамере $P_{0}=0.8$ атм. Результаты получены для двух величин объема каверны, за который здесь принят объем всей полости между двумя боковыми стеноками от кавитатора до входа в сопло плюс объем трубы, соединяющей входной вентиль 8 (см. рис. 1) с плоской рабочей частью. Видно, что при объеме каверна $73 \mathrm{~cm}^{3}$ с увеличением поддува имеет место переход с более высокая частотной моды (2-я) на более низкую при $C_{q} \sim 10$. Вблизи $C_{q}=10$ имеет место перемежаемость двух частотных режимов и интенсивность пульсаций давления в этом режиме уменьшается (см. рис. 9,6$)$. Затем, по мере развития низкочастотного режима, интенсивность пульсация снова растет с увеличением поддува. Путем подключения дополнительной емкости объем каверны был увеличен до $199 \mathrm{~cm}^{3}$. Видно, что увеличение объема каверны влияет на режим автоколебаний - при увеличении объема каверны высокочастотного режима не наблюдается, а интенсивность автоколебаний монотонно растет с увеличением поддува. В то же время зависимость коэффициента давления в каверне от поддува остается неизменной для этих двух режимов. Заметим, что в этой серии опытов время истечения порций жидкости через сопло довольно велико и для оценок частот нельзя применять соображения, основанные только на оценке времени распространения жидких волн вдоль границы каверны.

\section{7. Ударное воздействие импульсных струй на экран}

На рис. 10, $a, \sigma$ показаны осциллограммы давления, в каверне (1) и в угловой точке экрана (2) (область удара струи). Измерения проводились при одинаковом объеме каверны и избыточном давлении напора $P_{0}=1.0$ атм, для двух значений коэффициента поддува: $C_{q}=5.1$ (рис. $10, a$ - высокочастотные автоколебания), $C_{q}=14.8$ (рис. $10, \sigma$ - низкочастотный режим). Видно, что с ростом интенсивности автоколебаний в гидравлической системе растет и ударное - импульсное воздействие жидкости на экран, причем, на каждом периоде наиболее интенсивно воздействует первая порция жидкости, которая достигает экрана даже раньше, чем давление в каверне достигает максимума.
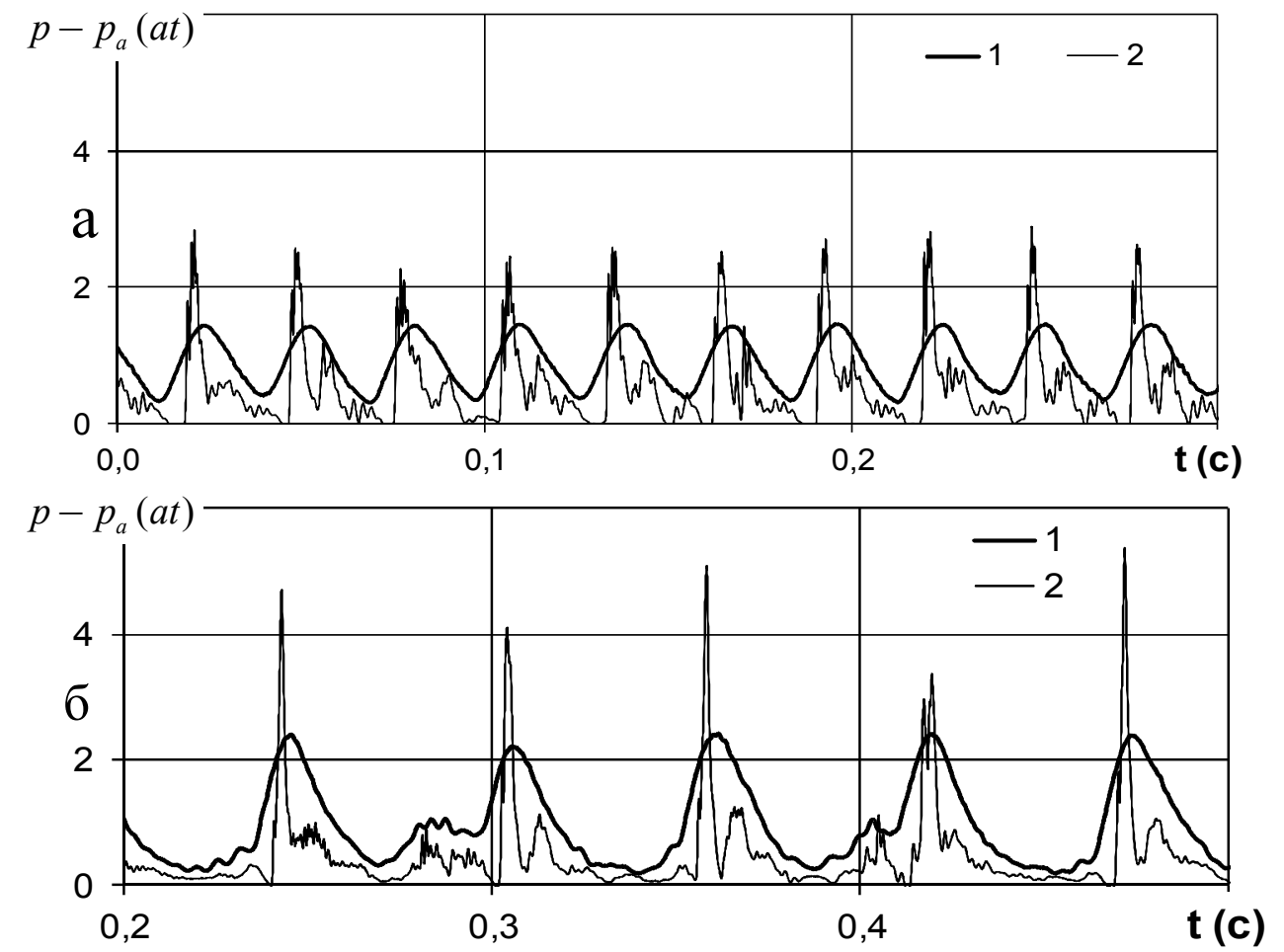

Рис. 10. Осциллограммы $p_{k}-p_{a}$ (1) и $p_{m}-p_{a}$ (2) (в атмосферах). $a-$ при $P_{0}=1.0$ атм, $S h=0.06, C_{q}=5.1 ; \sigma-$ при $P_{0}=1.0$ атм, $S h=0.03, C_{q}=14.8$ 
На рис. $10, a, \sigma$ видно, что максимум давления на экране значительно превосходит максимальное давление в каверне.

Исследования показали, что в принятой конфигурации течения (см. рис. 8) в окрестности угловой точки образуется застойная зона (хорошо видная при стационарном истечении струи), поэтому измеряемое в ней давление значительна меньше (даже в стационарном случае) чем при ударе порции жидкости о бесконечный экран. Однако, даже в таких условиях фиксируются ударные давления значительно превосходящее максимальное давление в каверне, что свидетельствует о наличии ударного взаимодействия струи с экраном.

\section{3. Упрощенная модель помпажного режима.}

Как показано на рис. 3, б в помпажный режим можно рассматривать как периодическую последовательности «выстрелов» жидкими массами, между выстрелами давление в полости близко к атмосферному. Это позволяет рассмотреть процесс выстрела как отдельный акт выбрасывания конечной жидкой массы через сопло в атмосферу. Итак, исходя из результатов экспериментальных наблюдений, начальное давление в каверне положим равным атмосферному, массу порции жидкости определим как произведение периода автоколебаний на средний расходом жидкости, начальную скорость жидкой массы положим равной $V_{k}$, pacход поддуваемого в каверну газа постоянен во времени. Задавая коэффициент расхода поддуваемого газа $C_{q}$, определяем коэффициент давления $C_{d}$ (а, следовательно, и скорость $V_{k}$ ) как функцию $C_{q}$ из эксперимента.

Применим уравнения одномерной нестационарной гидравлики для расчета движение в канале переменного сечения с учетом трения о стенки, для конечной массы жидкости, занимающей область $\left[x_{2}, x_{1}\right]$ (рис. 11$)$.

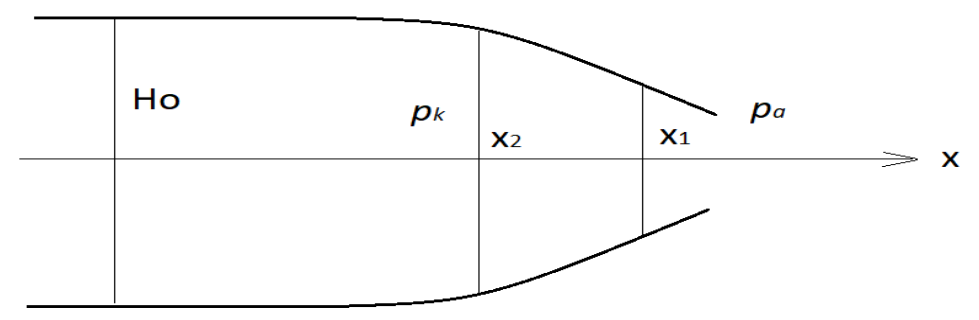

Рис. 11. Схема течения конечной массы жидкости в сужающемся сопле

Масса жидкости определяется заданным расходом жидкости и, определяемым из решения временем, равным времени прохождения волны от кавитатора до входа в сопло и временем движения жидкой массы в сопле. При $x=x_{2}$ давление равно давлению в каверне $p_{k}$, при $x=x_{1}$ - атмосферному. Давление в каверне определялось по изотермическому закону при известном массовом расходе газа, объем каверны равен объему полости плюс переменная часть объема сопла (от входа до координаты $x=x_{2}$ ). Для расчета выбрано сопло состоящее из равномерной части шириной $H_{0}$ и сужающейся (рис. 12,a), начальная скорость на входе в сопло полагалась равной $V_{k}$, начальное давление в каверне атмосферное. Расчет здесь проводится до момента, когда координата х1 достигает выходного сечения сопла, входное сечение сопла соответствует координате $x=0$.

На рис. 12 приведены примеры расчетов: здесь все длины отнесены к $H_{0}$. На рис. 12, $a, 8$ показана зависимость избыточного давления в каверне, отнесенного к $q=\rho V_{\infty}^{2} / 2=P_{0}$ от координаты передней границы жидкой массы $x_{1} / H_{0}$. На рис. $12, a$ показана также форма сопла (равномерная часть имеет длину 2 калибра, линейно сужающаяся также 2 калибра). Соотношения размеров сопла близки к экспериментальным - $H_{0}=25$ мм, ширина выходного сечения $H_{e}=10$ мм $\left(H_{e} / H_{0}=0.4\right)$, длина сужающейся части 50 мм. На рис. 12, б, г показана зависимость скорости переднего фронта жидкой массы $V_{1} / V_{\infty}$ от той же координаты. 
Серия расчетов (рис. $12, a, \sigma)$ проведена при постоянном коэффициенте поддува $C_{q}=20$, постоянном объеме каверны $\Omega\left(\Omega / H_{0}^{3}=1.5\right)$ и различных давлениях в форкамере $\bar{p}_{0} / p_{a}=1.5,2,4,10,20$ (1-5, соответственно). При малых напорах наблюдается значительный масштабный эффект, который исчезает при $\bar{p}_{0} / p_{a}>4$. Это означает, что для моделирования высокоскоростных струй достаточно провести исследования при избыточном давлении $P_{0}=3$ атм.
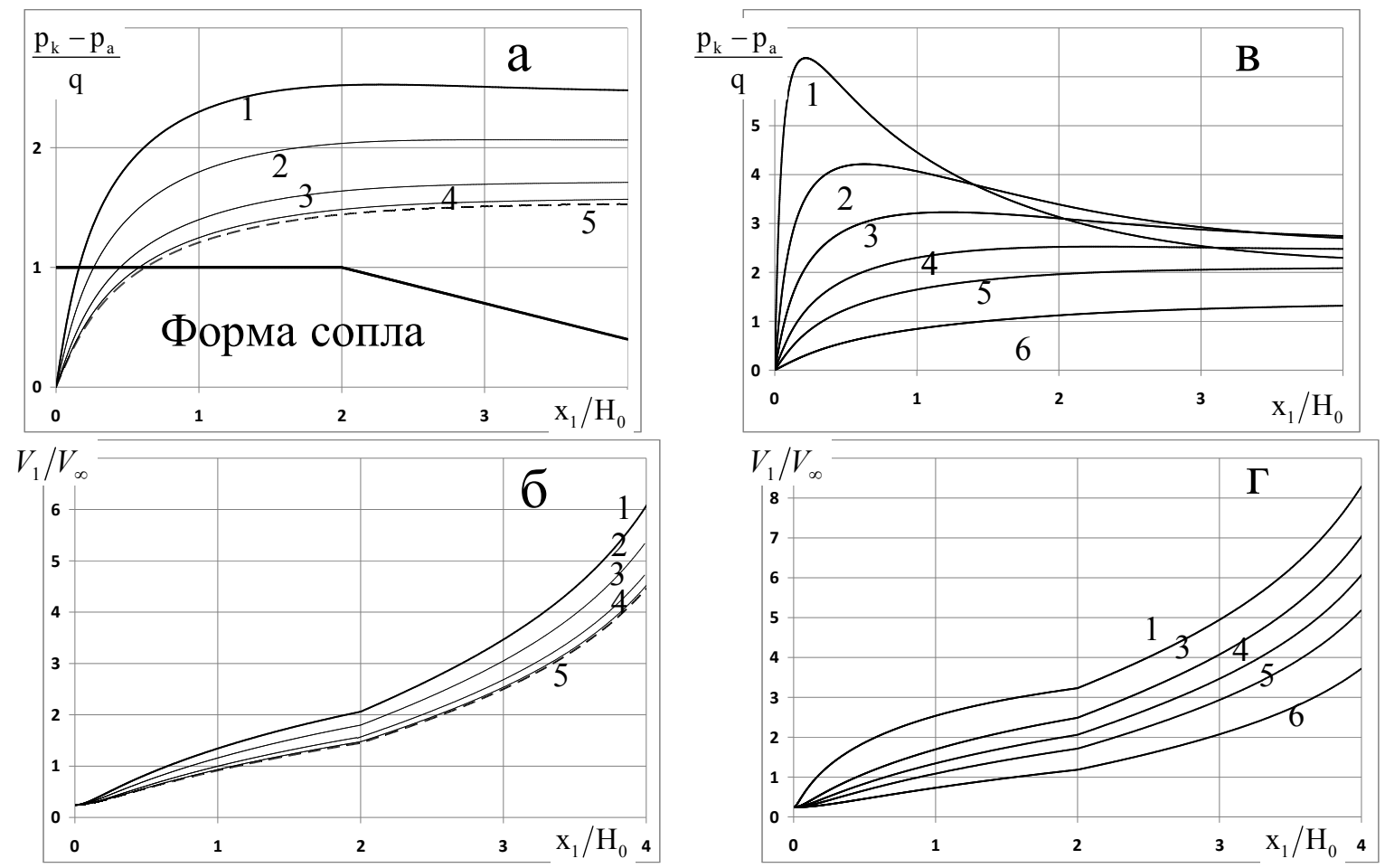

Рис. 12. Примеры расчетов процесса истечения жидкости через сопло. Зависимости безразмерного давления в каверне $(a, b)$ и скорости передней границы $(\sigma, 2)$ от координаты передней границы истекающей жидкой массы

Другая серия расчетов (рис. $12,6,2)$ проведена для постоянных $C_{q}=20$ и $\bar{p}_{0} / p_{a}=1.5$, но для различных величин объема каверны $\left(\Omega / H_{0}^{3}=0.7,1,1.5,2.5,3,10\right.$, кривые $1-6$ на рис. $12,6,2$, соответственно). Экспериментальная осциллограмма на рис. 10,6 получена при относительном объеме каверны $\Omega / H_{0}^{3} \sim 8$ (на рис. 12, в соответствующие данные находятся между кривыми 5 и 6), относительный размах колебаний давления в эксперименте примерно равен 2. Максимальные расчетные значения относительного давления на кривых 5 и 6 равны 2.1 и 1.2, соответственно (см. рис. 12, в), что количественно близко к экспериментальной величине. Видно, что при дальнейшем уменьшением объема каверны сильно возрастает амплитуда пульсаций давления в каверне, а скорость на выходе превосходит стационарную в 8 раз. Следовательно, для увеличения интенсивности удара нужно уменьшать объем кавитационной полости, однако нужно иметь в виду, что здесь возможен переход на другую частотную моду автоколебаний (см. п. 2.6.).

\section{4. Заключение}

Экспериментально исследовано течения с образованием в гидравлической магистрали за некоторым сопротивлением (кавитатором), вентилируемой каверны, длина которой ограничена вторым гидравлическим сопротивлением (щель или сопло).

Обнаружено, что при одинаковых геометрических параметрах течения возможны различные моды кавитационных автоколебаний, которые зависят от свойств подводящих труб и 
от объема каверны. Режимы высоких мод для создания импульсных струй непригодны так как наиболее интенсивные пульсации давления имеют место в форкамере, а колебания давления в каверне невелики.

Исследование влияния выходного сопротивления (истечение через щель или сужающееся сопло) показали, что с ростом сопротивления растет не только коэффициент давления $\mathrm{C}_{\mathrm{d}}$, но и интенсивность пульсаций давления в каверне, что приводит к образованию более интенсивных импульсных струй. Однако, очень большое выходное сопротивление приводит к прорыву газа в форкамеру, нарушает регулярность пульсаций и приводит к разрушению автоколебательного режима.

Показано, что с помощью сужающегося сопла можно создать режим струйного истечения, причем, скорость переднего фронта струи на выходе из сопла значительно превосходит скорость стационарного истечения.

Измерялось импульсное давление в области взаимодействия струи с перпендикулярным экраном. Показано, что существуют режимы, когда это давление значительно превосходит максимальное давление в каверне.

С привлечением экспериментальных данных для моделирования истечения жидкости через сопло при помпажном режиме применены уравнения одномерной нестационарной гидравлики с учетом трения. Расчеты показали, что масштабный эффект, исчезает при отношении среднего давления в форкамере к атмосферному $\bar{p}_{0} / p_{a}>4$. Показано также, что с уменьшением объема каверны при прочих постоянных параметрах сильно возрастает амплитуда пульсаций давления в каверне, и скорость на выходе значительно превосходит стационарную.

\section{Благодарности и ссылки на гранты}

Работа выполнена при поддержке гранта РФФИ № 18-01-00040

\section{Литература}

1. Фролов В.С. Исследование гидравлических способов разрушения горных пород стационарных и перемещающихся струй // Научные сообщения. - М.: ИГД им. А.А. Скочинского, 1975. № 134.

2. Сигаев Е.А. Исследование гидроотбойки пульсирующими гидромониторными струями // Известия ВУЗов. Горный журнал, 1964. - Вып. 2.

3. Зима П.Ф. и др. Создание агрегата для выемки ниш высоконапорными импульсными струями актуальная и перспективная задача (Рукопись деп. В Укр. НИИНТИ 18.08.86 № 1945 - Ук 86).

4. Носенко В.М. Предварительные испытания модели гидромонитора с подвижной насадкой // Труды института горного дела АН Казахской ССР. - 1963. - Т.43.

5. Савченко Н.В., Яхно О.М. Гидродинамические способы создания пульсирующих струй для гидроразрушения твердых материалов. НТУУ «КПИ», 2017.

6. Козлов И.И., Прокофьев В.В. Закономерности развития волн на поверхности каверны с отрицательным числом кавитации // Доклады РАН. 2006. том 409. № 1. С. $43-47$.

7. Козлов И.И., Очеретяный С.А., Прокофьев В.В. Влияние свойств подводящего трубопровода на характер кавитационных автоколебаний при наличии в системе вентилируемой каверны с отрицательным числом кавитации // Изв. РАН МЖГ. 2013. №2. С. 32-43.

8. Козлов И.И., Очеретяный С.А., Прокофьев В.В. О различных модах автоколебаний в течениях с вентилируемой каверной и возможности их использования для формирования периодических импульсных // Изв. РАН МЖГ, 2019, №3, С. 16-27.

9. Шкапов П.М., Благовещенский И.Г., Гартиг Е.Б. О гистерезисном характере развития автоколебаний в гидролинии с ограниченной искусственной газовой каверной на выходе. Наука и образование: научное издание МГТУ им. Н.Э. Баумана. 2013. № 10. 
10. Войцеховский Б.В., Лаврентьев М.А., Антонов Э.А. Вопросы теории и практики импульсных водяных струй, СО АНСССР, Ин-т гидродинамики, Н, 1960, 26

Статья поступила в редакцию 5 сентября 2019г. 